\title{
Diagnostic yield of transbronchial cryobiopsy in non-neoplastic lung disease: a retrospective case series
}

Sergej Griff ${ }^{*}$, Nicolas Schönfeld ${ }^{2}$, Wilhelm Ammenwerth², Torsten-Gerriet Blum² ${ }^{2}$ Christian Grah ${ }^{3}$, Torsten T Bauer ${ }^{2}$, Wolfram Grüning ${ }^{4}$, Thomas Mairinger ${ }^{1}$ and Henrik Wurps ${ }^{2}$

\begin{abstract}
Background: Due to the small amount of alveolar tissue in transbronchial biopsy (TBB) by forceps, the diagnosis of diffuse, parenchymal lung diseases (DPLD) is inherently problematic, with an overall low yield. The use of cryotechnique in bronchoscopy, including TBB by cryoprobe, has revealed new opportunities in the endoscopical diagnosis of malignant and non-malignant lung diseases.

Methods: To evaluate TBB by cryotechnique for non-neoplastic lung diseases, we analyzed 52 patients (mean age $63 \pm 13$ years) with unclear DPLD. These individuals underwent bronchoscopy with TBB by cryoprobe. Thereafter histopathological results were compared with the clinically evaluated diagnosis.

Results: No major complications were seen. Mean specimen diameter in the histological biopsies was $6.9 \pm 4.4 \mathrm{~mm}$ (Range $2-22 \mathrm{~mm}$ ). A correlation between clinical and histopathological diagnoses was found in $79 \%$ of cases (41/52). In the case of UIP (usual interstitial pneumonia) pattern, the concordance was 10/15 (66\%).
\end{abstract}

Conclusion: Based on these results TBB by cryotechnique would appear to be a safe and useful method that reveals new perspectives for the endoscopical diagnosis of DPLD.

Keywords: Diffuse parenchymal lung disease (DPLD), Bronchoscopy, Transbronchial biopsy (TBB), Cryotechnique, Histopathology, Usual interstitial pneumonia (UIP)

\section{Background}

Concerning transbronchial lung biopsy (TBB) by forceps, histopathological results depend on specimen size and quality, artificial changes due to the procedure itself, and the amount of alveolar tissue contained in the sample. TBB by forceps typically delivers one or more 1-2 mm sized specimen, often with underrepresentation of alveolar tissue [1-4].

Due to the large variation of indications, as well as different sizes and locations of pulmonary lesions, diagnostic yield of TBB by forceps is severe to describe. Most recent case series specify a diagnostic accuracy of about $50 \%$ to $70 \%[1,3,5-11]$.

\footnotetext{
* Correspondence: sergej.griff@helios-kliniken.de

${ }^{1}$ Institute of Pathology, HELIOS Klinikum Emil von Behring, Walterhöferstr. 11, 14165 Berlin, Germany

Full list of author information is available at the end of the article
}

Diffuse parenchymal lung diseases (DPLD) are harder to diagnose by TBB with an overall lower yield. Efficacy variations depend on the underlying disease: Sarcoidosis and cryptogenic organizing pneumonia (COP) render fairly good results, whereas usual interstitial pneumonia (UIP), pneumoconiosis, respiratory bronchiolitis associated interstitial lung disease (RB-ILD), non specific interstitial pneumonia (NSIP) and pulmonary histiocytosis $\mathrm{X}$ show poor results $[1,4,10,12,13]$. This broad range is explained by the diverging importance of alveolar tissue for the histopathological diagnosis.

Due to the small yield of alveoli in TBB by forceps it is not possible to gather further information concerning the histopathological pattern of affected tissue throughout the lung. This problem is well known and has recently been discussed in literature [1,3,4,6,13-17]. Some papers do show an increase of diagnostic yield depending on the size of the specimen $[6,14]$, however 
artificial changes due to TBB by forceps are an important limiting criterion for the pathological diagnosis of DPLD.

Cryobiopsy as a tool in bronchology has been introduced on a routine basis in recent years and has been found to be safe in a routine diagnostic setting $[18,19]$. Specimen size has been reported to be larger and diagnostically more valuable due to more alveolar tissue and less artificial changes. In a previous paper morphometrical benefits of cryobioptically obtained lung tissue specimen were shown and perspectives of this method in a daily routine were discussed [20]. There is evidence that cryobiopsies increase efficacy concerning histopathological tumor diagnostics in central malignant lesions $[19,21]$.

The aim of this study was to evaluate TBB by cryotechnique for non-neoplastic diseases. Our focus was sample adequacy for diagnostic purposes, sample size and proportion of alveolar tissue retrieved, as well as the possibility of histopathological diagnosis of DPLD by cryobiopsy in correlation to clinical diagnoses.

\section{Methods}

This is a retrospective case series (June 2009 - December 2011) of 52 patients with diffuse, interstitial, nonneoplastic lung diseases who underwent flexible, fiberoptic bronchoscopy with transbronchial cryobiopsy. Additionally, all patients had routine diagnostics including lung function evaluation, chest $\mathrm{x}$-ray and thoracic computed tomography (CT-scan).

For the transbronchial cryobiopsy a flexible cryoprobe with a diameter of $1.9 \mathrm{~mm}$ was used (flexible Kryosonde diameter $1.9 \mathrm{~mm}$ length $900 \mathrm{~mm}$, Erbe Elektromedizin $\mathrm{GmbH}$, Tübingen, Germany), the probe was cooled to a temperature of about $-77^{\circ} \mathrm{C}$ by carbon dioxide. The flexible bronchoscopy (1 T 160 and $1 \mathrm{~T}$ 180, Olympus Corp. Tokyo Japan) was performed under sedation with disoprivan or midazolam and local anaesthesia with lidocaine. The cryoprobe was introduced into the selected area with a distance of approximately $1-2 \mathrm{~cm}$ from the thoracic wall under radiological guidance. In this position the cryoprobe was cooled for three to five seconds and then retracted with the attached frozen lung tissue. For each patient one to two specimen were taken and then fixed in $4 \%$ buffered formalin.

To avoid incomplete sectioning of specimen particles all biopsies were conventionally processed by serial sectioning of at least $12 \mathrm{H}$ \& E stained section steps. Concerning quantity, quality (number of artefacts), and the amount of alveolar tissue, the biopsies were rated by two experienced lung pathologists (SG \& TM).

Mirax Viewer Image Software Ver $(1,6)$ was used for scanning the Hematoxylin-eosine slides by a ZEISSMIRAX Midi Slide scanning system (Zeiss Microimaging, Oberkochen, Germany and 3DTech, Budapest, Hungary).
The total diameter of the biopsy specimens were measured and expressed in $\mu \mathrm{m}$.

Histopathological changes were rated according to criteria for UIP diagnosis based on the Official ATS/ERS/ JRS/ALAT Statement (22). The histological diagnosis of other entities was made by the use of classical criteria for interstial lung diseases (4).

Histopathological results and radiographic images were compared to the patients' medical history, physical examination and data of pulmonary lung function testing. At last, in an interdisciplinary setting (pathologist, radiologist, pneumologist) a diagnosis was found. Furthermore, complications seen during bronchoscopy were rated.

Statistically, results were expressed as frequencies or as mean $\pm \mathrm{SD}$. Chi-square-test was used to compare proportions. The significance level of the analyses was set to $5 \%$, and exact $p$ values were reported. Results were expressed using descriptive statistics.

Statistical software (Statistical Package for Social Sciences, Version 14.0; SPSS, Chicago, IL, USA) was used to analyze and process the data on a Windows XP operating system (Microsoft; Redmond, WA, USA).

A waiver for this study was received by the ethics committee of the Charité, Berlin, Germany ("Ethikkommission, Ethikausschuss 1 am Campus Charité - Mitte") on January 23, 2014.

\section{Results}

Overall, 52 patients with a median age of $63 \pm 13$ years were analyzed. 36/52 (69\%) patients were male, 16/52 (31\%) were female. In $41 / 52$ cases $(79 \%)$ a correlation with clinical and histopathological diagnosis was found. In $11 / 52$ cases (21\%) no match could be achieved.

Mean specimen diameter in the histological biopsies was $6.9 \pm 4.4 \mathrm{~mm}$ (Range $2-22 \mathrm{~mm}$ ). In the specimen, alveolar tissue was found in 48/52 (92\%) cases. In 4/52 (8\%) cases no alveolar tissue was found. In one of these four cases no histopathological diagnosis could be matched to the clinical diagnosis due to the lack of alveolar tissue. In the other three cases the diagnosis was sarcoidosis, and typical granulomas were found in the bronchial mucosa. The specimens lacking alveolar tissue either contained only bronchial mucosa and sometimes cartilage, or presented themselves as long flat bands of inner bronchial wall lining.

No major complications (pneumothorax, major bleeding $>3$ minutes) with need of further intervention were reported.

Table 1 shows the list of clinically diagnosed lung diseases, the number of matching histopathological findings and the average diagnostic yield of TBB by forceps reported in literature.

The HR-CT images of patients who had the clincal diagnosis of idiopathical lung fibrosis (IPF) or pulmonary 


\begin{tabular}{|c|c|c|c|}
\hline $\begin{array}{l}\text { Clinical } \\
\text { diagnosis }\end{array}$ & $\begin{array}{l}\text { Number } \\
\text { of cases }\end{array}$ & $\begin{array}{l}\text { Matching } \\
\text { histopathological } \\
\text { findings }\end{array}$ & $\begin{array}{l}\text { Average reported } \\
\text { diagnostic yield } \\
\text { by forceps biopsy }\end{array}$ \\
\hline $\mathrm{COP}$ & 9 & 8/9 (89\%) & $65 \%(10,27,28)$ \\
\hline $\begin{array}{l}\text { Rheumatoid } \\
\text { lung disease }\end{array}$ & 2 & $2 / 2(100 \%)$ & \\
\hline Sarcoidosis & 12 & 10/12 (83\%) & $69 \%(10,28,29)$ \\
\hline $\begin{array}{l}\text { Alveolar } \\
\text { microlithiasis }\end{array}$ & 1 & 1/1 (100\%) & - \\
\hline NSIP & 1 & $1 / 1(100 \%)$ & - \\
\hline $\begin{array}{l}\text { medically-induced } \\
\text { lung damages }\end{array}$ & 2 & 2/2 (100\%) & - \\
\hline $\mathrm{HP}$ & 7 & 6/7 (86\%) & $95 \%(10)$ \\
\hline $\begin{array}{l}\text { Pulmonary } \\
\text { manifestation of } \\
\text { scleroderma }\end{array}$ & 2 & $1 / 2(50 \%)$ & - \\
\hline Histiocytosis & 2 & $1 / 2(50 \%)$ & - \\
\hline $\begin{array}{l}\text { pANCA-pos. } \\
\text { Vasculitis }\end{array}$ & 1 & 0/1 (0\%) & - \\
\hline IPF & 13 & 9/13 (69\%) & $34 \%(1,10)$ \\
\hline
\end{tabular}

manifestation of scleroderma were rated apropos of the radiological criteria for UIP after ATS (American Thoracic Society) and ERS (European Respiratory Society) $[22,23]$. Of these fifteen cases, fourteen $(93 \%)$ showed possible or probable UIP pattern and one (7\%) was inconsistent with UIP pattern.

\section{Discussion}

Cryobiopsy in our series proved to be a sufficient tool in the diagnostic processing for various diffuse, parenchymal lung diseases (DPLD). Specifically, the highest diagnostic yields were achieved in patients with sarcoidosis $(83 \%)$, COP $(89 \%)$, and hypersensitivity pneumonia (HP, 86\%). Comparable results with the use of transbronchial forceps biopsy have been reported in recent years [1,3,5-10] (see Table 1). These good results are probably due to the location of granulomatous or other characteristic changes close to or within the bronchial wall.

Nevertheless clear distinctions became obvious between diseases that required the recognition of a gross histological pattern (UIP, NSIP, RB-ILD) and all others.

It has generally been assumed that transbronchial lung biopsies cannot be used for the diagnosis of UIP [10]. A hallmark characteristic of UIP is the patchy involvement of lung tissue, so that areas of involved parenchyma and unaffected alveoli stand next to each other. Furthermore, UIP is characterized histologically by fibrosis and chronic inflammation, i.e. features that are usual unspecific findings located in the peribronchial tissue.

In a study by Berbescu et al. [1], 22 patients with UIP pattern assessed by open lung biopsy were retrospectively analyzed concerning a pre-op achieved TBB. This revealed a characteristic histopathological UIP pattern in nine cases. Berbescu et al. concluded [1] that certain characteristic features of UIP, such as the patchwork pattern of involvement by fibrosis and temporal variability with fibroblast foci, collagen, and honeycomb changes, previously thought to be recognizable only on surgical lung biopsy specimen, can sometimes be seen on TBB specimen. The patchwork pattern is typically characterized by normal alveoli in close relation to areas of interstitial fibrosis. Its presence helps to distinguish the changes to nonspecific peribronchial fibrosis where there is a gradual transition from normal to abnormal.

In our series of transbronchial cryobiopsies an UIP pattern was diagnosed in two-thirds $(10 / 15,67 \%)$ of the

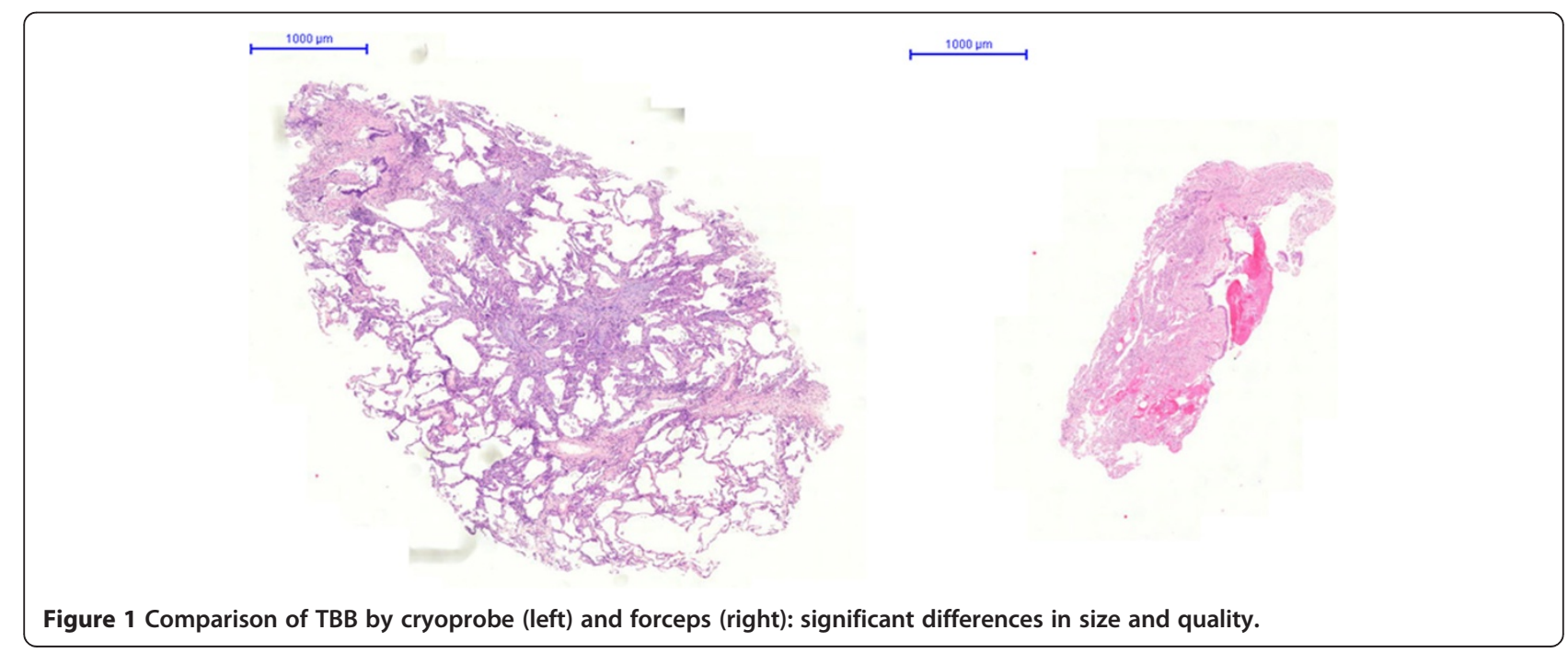




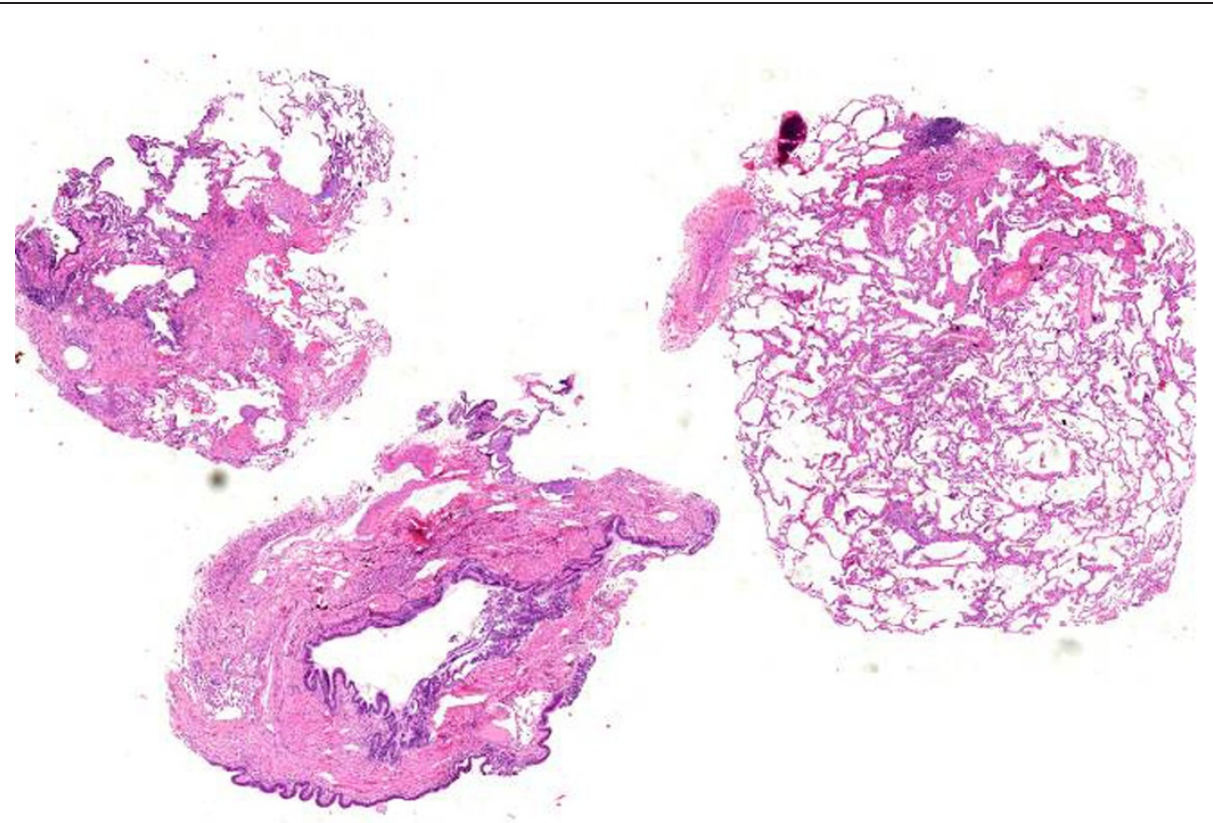

Figure 2 Patient with radiological UIP pattern. Overview of transbronchial cryobiopsy: patchy involvement of fibrosing process next to unaffected lung tissue.

cases (IPF, pulmonary manifestation of scleroderma, see Table 1). This improves the diagnostic yield of TBB for UIP pattern in comparison to data described in literature by up to $50 \%$ (see Table 1 ).

Cryobiopsy specimen tend to be even larger than transbronchial forceps biopsy specimen, and contain more and larger amounts of alveolar tissue [21]. In a previous study the number of alveolar spaces necessary for an adequate biopsy was defined as 20 [6]. This criterion is likely to be fulfilled in most of the cryobiopsy

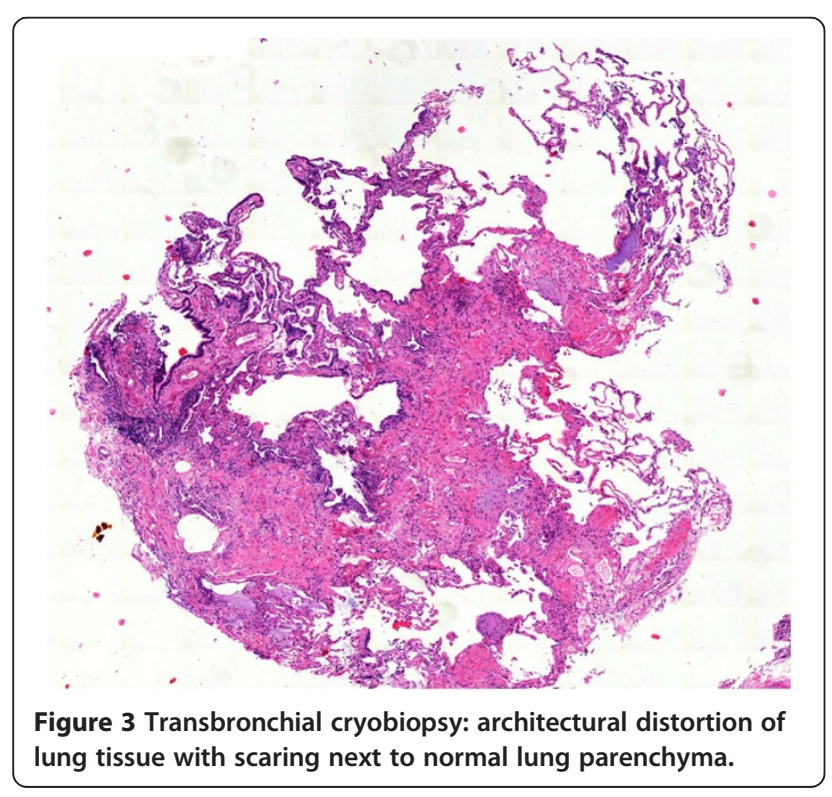

specimen ([21]; unpublished data). However, transbronchial cryobiopsy, as well as TBB by forceps, fail to deliver the diagnosis of UIP in a significant proportion of patients. This may be due to the distance seen frequently between the bronchial wall and typical histological changes, such as fibroblast foci, which are located deeply in the alveolar parenchyma [1] (Figures 1, 2, 3, 4).

Despite the encouraging findings about cryobiopsy these results do not yet command a recommendation of transbronchial cryobiopsy as a standard procedure in the

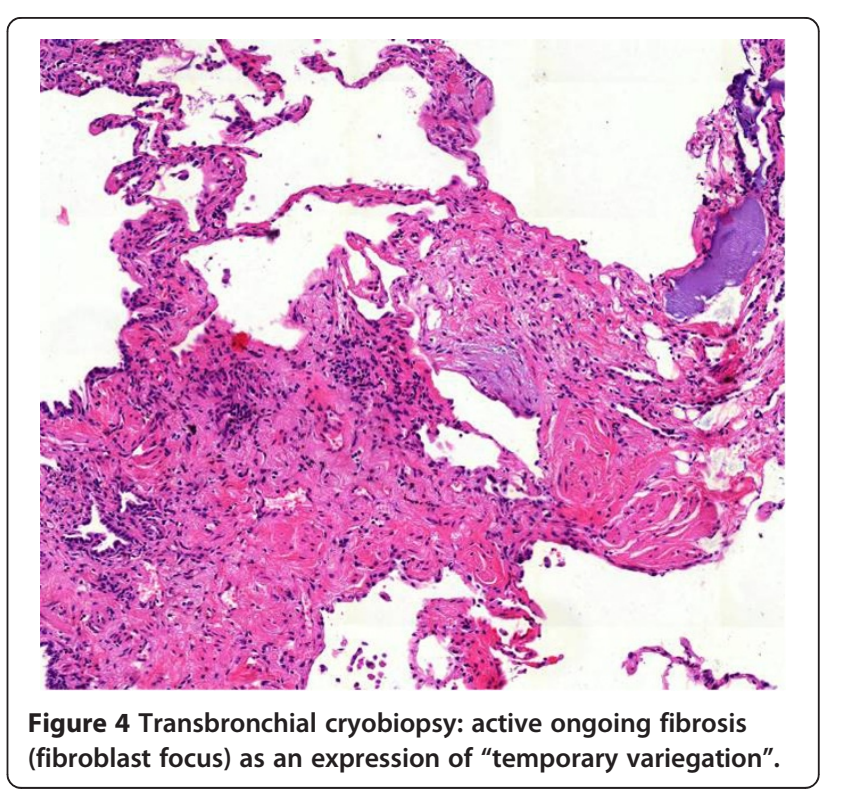


processing of suspected pulmonary fibrosis. Nevertheless, the current problem of distinguishing between HP with UIP pattern and IPF (which radiologically speaking cannot be securely discriminated [24]) could be solved by the use of cryobiopsy with greater specimen size. Furthermore, there is a greater chance for detection of granulomas or other characteristic histopathological features [25-29]. Therefore larger prospective and comparative series must be evaluated before a general clinical algorithm can be proposed. Meanwhile, in those individual patients where cryobiopsy has revealed the full pattern of UIP, open lung biopsy is unnecessary if histology and clinical data engender a clear diagnosis.

\section{Conclusions}

Cryobiopsy could improve the results reported on conventional transbronchial forceps biopsy. Nevertheless, previously reported series are small and prospective comparisons do not exist. Such studies could even reveal that eventually less cryobiopsy pieces per patient are necessary as compared to transbronchial forceps biopsies. For the latter most of the authors recommend four biopsies per bronchoscopy during the processing of diffuse lung disease. In our present series only 1-2 cryobiopsy specimen were sampled as a rule.

The high diagnostic yield and the lack of any major complication in our series encourages one to proceed with larger studies and to establish transbronchial cryobiopsy within routine clinical algorithms in the diagnostic of diffuse, parenchymal lung disease.

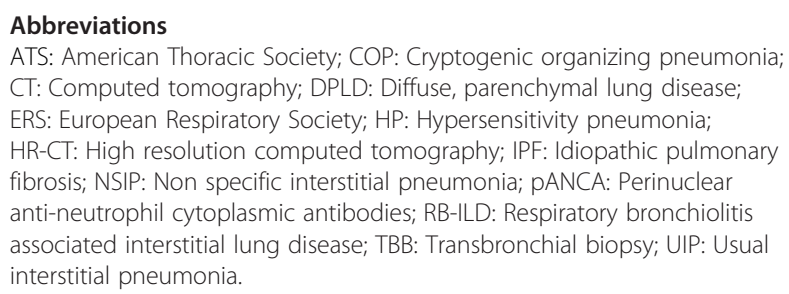

\section{Competing interests}

The authors declare that they have no competing interests.

\section{Authors' contributions}

SG performed the histological analysis of the samples and drafted the manuscript. NS participated in the design of the study and helped drafting the manuscript. WA performed bronchoscopy, took samples and helped in the coordination of the manuscript. TB performed the statistical analysis. CG performed bronchoscopy and took samples. TB participated in the design of the study and helped in the draft. WG performed bronchoscopy and took samples. TM performed the histological analysis of the samples and helped to draft the manuscript. HW performed bronchoscopy, took samples and drafted the manuscript. All authors read and approved the final manuscript.

\section{Acknowledgments}

This work is a part of the doctoral thesis of main author Sergej Griff, being performed at the Charité - University of Medicine in Berlin, Germany.

\section{Author details}

'Institute of Pathology, HELIOS Klinikum Emil von Behring, Walterhöferstr. 11, 14165 Berlin, Germany. ${ }^{2}$ Clinic of Pneumology, Lungenklinik Heckeshorn,
HELIOS Klinikum Emil von Behring, Berlin, Germany. ${ }^{3}$ Medical Clinic of Pneumology, Gemeinschaftskrankenhaus Havelhöhe, Berlin, Germany. ${ }^{4}$ Clinic of Pneumology, HELIOS-Kliniken Schwerin, Schwerin, Germany.

Received: 30 August 2014 Accepted: 23 October 2014

Published: 3 November 2014

\section{References}

1. Berbescu EA, Katzenstein AL, Snow JL, Zisman DA: Transbronchial biopsy in usual interstitial pneumonia. Chest 2006, 129(5):1126-1131.

2. Katzenstein AL, Askin FB: Interpetation and significance of pathologic findings in transbronchial lung biopsy. Am J Surg Pathol 1980, 4(3):223-234.

3. Joyner LR, Scheinhorn DJ: Transbronchial forceps lung biopsy through the fiberotic bronchoscope, diagnosis of diffuse pulmonary disease. Chest 1975, 67:532-535.

4. Katzenstein AL: Katzenstein and Askin's Surgical Pathology of Non-Neoplastic Lung Disease. 4th edition. Philadelphia, USA: Saunders Company; 2006.

5. Zavala DC: Diagnostic fiberoptic bronchoscopy, techniques and results of biopsy in 600 patients. Chest 1975, 68:12-19.

6. Fraire AE, Cooper SP, Greenberg SD, Rowland LP, Langston C: Transbronchial lung biopsy: histopathologic and morphometric assessment of diagnostic utility. Chest 1992, 102:748-752.

7. Payne CR, Hadfield JW, Stovin PG, Barker V, Heard BE, Stark JE: Diagnostic accuracy of cytology and biopsy in primary bronchial carcinoma. J Clin Pathol 1981, 34:773-778.

8. Rudd RM, Gellert AR, Boldy DAR, Studdy PR, Pearson MC, Geddes DM, Sinha $\mathrm{G}:$ Bronchoscopic and percutaneus aspiration biopsy in the diagnosis of brochial cell type. Thorax 1982, 37:462-465.

9. Franke KJ, Nilius G, Rühle KH: Bronchocopic diagnosis of peripheral pulmonary foci. Dtsch Med Wochenschr 2006, 131:2229-2233.

10. Descombes E, Gardiol D, Leuenberger P: Transbronchial lung biopsy: an analysis of 530 cases with reference to the number of samples. Monaldi Arch Chest Dis 1997, 52(4):324-329.

11. Baaklini WA, Reinoso MA, Gorin AB, Sharafkaneh A, Manian P: Diagnostic yield of fiberoptic bronchoscopy in evaluating solitary pulmonary nodules. Chest 2000, 117:1049-1054.

12. Schönfeld N, Frank W, Wenig S, Uhrmeister P, Allica E, Preussler H, Grassot A, Loddenkemper R: Clinical and radiologic features, lung function and therapeutic results in pulmonary histiocytosis X. Respiration 1993, 60(1):38-44.

13. Ryu JH, Myers JL, Capizzi SA, Duoglas WW, Vassallo R, Decker PA: Desquamative interstitial pneumonia and respiratory bronchiolitisassociated interstitial lung disease. Chest 2005, 127:178-184.

14. Casoni GL, Gurioli C, Chhajed PN, Chilosi M, Zompatori M, Olivieri D, Poletti $\mathrm{V}$ : The value of transbronchial lung biopsy using jumbo forceps via rigid bronchoscope in diffuse lung disease. Monaldi Arch Chest Dis 2008, 69(2):59-64.

15. Oliveira CC, Fabro AT, Ribeiro SM, Defaveri J, Capelozzi VL, Queluz THT, Yoo HHB: Evaluation of the use of transbronchial biopsy in patients with clinical suspicion of interstitial lung disease. J Bras Pneumol 2011, 37(2):168-175

16. Romagnoli M, Bigliazzi C, Casoni G, Chilosi M, Carloni A, Dubini A, Gurioli C, Tomassetti S: The role of transbronchial lung biopsy for the diagnosis of diffuse drug-induced lung disease: a case series of 44 patients. Sarcoidosis Vasc Diffuse Lung Dis 2008, 25(1):36-45.

17. Shim HS, Park MS, Park IK: Histopathologic findings of transbronchial biopsy in usual interstitial pneumonia. Pathol Int 2010, 60(5):373-377.

18. Franke KJ, Theegarten D, Hann von Weyhern C, Nilius G, Brueckner C, Hetzel J, Hetzel M, Ruhle KH, Enderle MD, Szyrach MN: Prospective controlled animal study on biopsy sampling with new flexible cryoprobes versus forceps: evaluation of biopsy size, histological quality and bleeding risk. Respiration 2010, 80(2):127-132.

19. Schumann C, Hetzel J, Babiak AJ, Merk T, Wibmer T, Möller P, Lepper PM, Hetzel M: Cryoprobe biopsy increases the diagnostic yield in endobronchial tumor lesions. J Thorac Cardiovasc Surg 2010, 140(2):417-421.

20. Griff $S$, Ammenwerth $W$, Schönfeld N, Bauer TT, Mairinger R, Blum T, Kollmeier J, Grüning W: Morphometrical analysis of transbronchial cryobiopsies. Diagn Pathol 2011, 6:53. 
21. Aktas Z, Gunay E, Hoca NT, Yilmaz A, Demirag F, Gunay S, Sipit T, Kurt EB: Endobronchial cryobiopsy or forceps biopsy for lung cancer diagnosis. Ann Thorac Med 2010, 5(4):242-246.

22. Raghu G, Collard HR, Egan JJ, Martinez FJ, Behr J, Brown KK, Colby TV, Cordier JF, Flaherty KR, Lasky JA, Lynch DA, Ryu JH, Swigris JJ, Wells AU, Ancochea J, Bouros D, Carvalho D, Costabel U, Ebina M, Hansell DM, Johkoh T, Kim DS, King TE Jr, Kondoh Y, Myers J, Müller NL, Nicholson AG, Richeldi L, Selman M, Dudden RF, et al: An official ATS/ERS/JRS/ALAT statement: idiopathic pulmonary fibrosis: evidence-based guidelines for diagnosis and management. Am J Respir Crit Care Med 2011, 183:794.

23. American Thoracic Society/European Respiratory Society: International multidisciplinary consensus classification of the idiopathic interstitial pneumonias. Am J Respir Crit Care Med 2002, 165:277-304.

24. Silva Cl, Müller NL, Lynch DA, Curran-Everett D, Brown KK, Lee KS, Chung MP, Churg A: Chronic hypersensitivity pneumonitis: differentiation from idiopathic pulmonary fibrosis and nonspecific interstitial pneumonia by using thin-section CT. Radiology 2008, 246(1):288-297.

25. Takemura T, Akashi T, Kamiya H, Ikushima S, Ando T, Oritsu M, Sawahata M, Ogura T: Pathological differentiation of chronic hypersensitivity pneumonitis from idiopathic pulmonary fibrosis/usual interstitial pneumonia. Histopathology 2012, 61(6):1026-1035.

26. Dina R, Sheppard MN: The histological diagnosis of clinically documented cases of cryptogenic organizing pneumonia: diagnostic features in transbronchial biopsies. Histopathology 1993, 23(6):541-545.

27. Jareno Esteban J, Zamora Garcia E, Chillon Martin MJ, Pérez Amor E, Villegas Fernández F, Forniés Menéndez E, Callol Sánchez L: Bronchiolitis obliterans with organizing pneumonia, usefulness and yield of diagnostic techniques and procedures in a series of 20 patients. An Med Interna 2001, 18(2):63-68.

28. Gerasin VA, Molodtsova VP, Dvorakovskaia IV, Derevianko AV, Bazhanov AA, Baranova OP: Transbronchial biopsy of the lungs in diagnosis of respiratory sarcoidosis. Ter Arkh 2008, 80(4):43-46.

29. Cucevic I, Cucevic B, Pongrac I, Roglic M: Comparative analysis of bronchoalveolar lavage and transbronchial lung biopsy in pulmonary sarcoidosis. Plucne Bolesti 1991, 43(1-2):106-108.

doi:10.1186/1471-2466-14-171

Cite this article as: Griff et al:: Diagnostic yield of transbronchial cryobiopsy in non-neoplastic lung disease: a retrospective case series. BMC Pulmonary Medicine 2014 14:171.

\section{Submit your next manuscript to BioMed Central and take full advantage of:}

- Convenient online submission

- Thorough peer review

- No space constraints or color figure charges

- Immediate publication on acceptance

- Inclusion in PubMed, CAS, Scopus and Google Scholar

- Research which is freely available for redistribution 